\title{
Fear and the Human Amygdala
}

\author{
Ralph Adolphs, ${ }^{1}$ Daniel Tranel, ${ }^{1}$ Hanna Damasio ${ }^{1,2}$ and Antonio R. Damasio ${ }^{1,2}$ \\ 'Department of Neurology, Division of Cognitive Neuroscience, University of lowa College of Medicine, lowa City, \\ lowa and ${ }^{2}$ The Salk Institute for Biological Studies, La Jolla, California
}

We have previously reported that bilateral amygdala damage in humans compromises the recognition of fear in facial expressions while leaving intact recognition of face identity (Adolphs et al., 1994). The present study aims at examining questions motivated by this finding. We addressed the possibility that unilateral amygdala damage might be sufficient to impair recognition of emotional expressions. We also obtained further data on our subject with bilateral amygdala damage, in order to elucidate possible mechanisms that could account for the impaired recognition of expressions of fear.

The results show that bilateral, but not unilateral, damage to the human amygdala impairs the processing of fearful facial expressions. This impairment appears to result from an insensitivity to the intensity of fear expressed by faces. We also confirmed a double dissociation between the recognition of facial expressions of fear, and the recognition of identity of a face: these two processes can be impaired independently, lending support to the idea that they are subserved in part by anatomically separate neural systems. Based on our data, and on what is known about the amygdala's connectivity, we propose that the amygdala is required to link visual representations of facial expressions, on the one hand, with representations that constitute the concept of fear, on the other. Preliminary data suggest the amygdala's role extends to both recognition and recall of fearful facial expressions.

[Key words: amygdala, emotion, affect, fear, facial expression, social cognition]

As borne out by two recent reports on human amygdala damage (Adolphs et al., 1994; Young et al., 1995), the amygdala is ideally suited to participate in processing visual stimuli that communicate emotional signiticance in social situations, such as facial expressions (Darwin, 1872/1965; Stein et al., 1990; Kling and Brothers, 1992). We previously reported that bilateral damage to the human amygdala impairs the recognition of fear in facial expressions (Adolphs et al., 1994). This finding left open the possibility that unilateral amygdala damage could produce the same deficit, a question we address here. An additional purpose of the present study is to provide a more complete characterization of the processing defect that results from

Received Feb. 8, 1995; revised Apr. 25, 1995; accepted Apr. 28, 1995.

We thank all subjects for their participation. This study was supported by NINDS Grant NS 19632. R.A. is a Burroughs-Wellcome Fund Fellow of the Life Sciences Research Foundation.

Correspondence should be addressed to Ralph Adolphs, Department of Neurology, 200 Hawkins Drive, Iowa City, IA 52242.

Copyright (C 1995 Society for Neuroscience 0270-6474/95/155879-13\$05.00/0 bilateral amygdala damage, in order to suggest mechanisms by which the amygdala helps to process stimuli related to fear.

Since our study involves vision and emotion, we briefly review the amygdala's rolc in these two domains. Highly processed visual information reaches the amygdala via temporal cortices, including areas TE, TEO, and the temporal pole (Herzog and Van Hoesen, 1976; Iwai and Yukie, 1987; Amaral et al., 1992). The inferotemporal cortex in the monkey contains neurons that respond selectively to the sight of faces and bodies of conspecifics. These responses can be selective for a particular face, or a particular view of faces or bodies, for a particular direction of gaze in the face, or for facial expressions (Perrett et al., 1982; Hasselmo et al., 1989; Wachsmuth et al., 1994). In humans, bilateral lesions of the temporal cortex are usually required to impair recognition of the identity of faces (Damasio et al., 1990), but unilateral lesions of the right temporal cortex can be sufficient to impair recognition of emotional expressions (Bowers and Heilman, 1984; Rapcsak et al., 1989; Rapcsak et al., 1993). While both the human (Heit et al., 1988; Allison et al., 1994) and monkey (Leonard et al., 1985; Rolls, 1992) amygdala also contain neurons that respond selectively to faces, little is known about the functional significance of this finding. Given our previous finding that bilateral amygdala damage causes specific deficits in recognizing facial expressions, we wanted (1) to investigate the unilateral contributions of the left and right amygdala independently, and (2) to show how specific to facial expressions of fear the deficits are.

Evidence suggesting that the amygdala participates in emotion is found in the close links between the amygdala and the autonomic nervous system (Chapman et al., 1954; LeDoux et al., 1988; Lee et al., 1988a; Amaral et al., 1992), as well as in the high densities of binding sites within the amygdala to substances that modulate fear and aggression, such as the benzodiazepines (Niehoff and Kuhar, 1983) and serotonin (Hensman et al., 1991; Saudou et al., 1994). Some neurons in the monkey amygdala respond to the affective significance (the rewarding or punishing contingencies) of sensory stimuli (Nishijo et al., 1988). Monkeys with lesions of the amygdala are insensitive to stimuli that normally arouse intense fear (Weiskrantz, 1956; Blanchard and Blanchard, 1972), and cannot be conditioned to associate stimuli with fear (Kapp et al., 1982; Hitchcock and Davis, 1986; LeDoux et al., 1990; Davis, 1992a,b). While many of these findings may extrapolate to humans, we wondered if the amygdala would be equally involved in processing components of the concept of fear that depend mostly on language, as well as those that depend mostly on nonverbal images. We show here that while bilateral amygdala damage impairs recognition of fearful facial expressions, and impairs their 
recall in imagery, it leaves relatively unaffected verbal knowledge related to fear.

\section{Materials and Methods}

\section{Subjects}

We compared target subjects, who all had damage to the amygdala, to a group of brain-damaged controls, who had no damage to the amygdala. The target subjects were chosen on the basis of neuroanatomical site of lesions, and consisted of one patient with bilateral damage to the amygdala, three patients with unilateral damage to the left, and three with unilateral damage to the right amygdala. Control subjects were 12 patients with brain damage, but intact amygdalae, and 7 normal individuals with no history of neurological or psychiatric disease. Both target and control brain-damaged subjects were selected from the $\mathrm{Pa}$ tient Registry of the Division of Behavioral Neurology and Cognitive Neuroscience at the University of Iowa, and had been fully characterized neuroanatomically and ncuropsychologically according to the standard protocols of the Benton Neuropsychology Laboratory (Tranel, 1995) and the Laboratory of Neuroimaging and Human Neuroanatomy (Damasio and Damasio, 1989; Damasio and Frank, 1992). For each subject, MR and/or CT scan data were available, and additional neuroanatomical analyses were carried out as necessary. Three-dimensional reconstructions of MR images were obtained for all target subjects in order to allow a detailed analysis of their lesions (Damasio and Frank, 1992). We excluded subjects who were significantly depressed, as assessed with the Beck Depression Inventory and the Minnesota Multiphasic Personality Inventory. All subjects used in our study had given informed consent to participate in research.

Bilateral amygdala lesions. Patient SM-046 had nearly complete bilateral amygdala lesions. This subject suffers from a rare, autosomal recessive, genetic disease, Urbach-Wicthe disease (IIofer, 1973), which has resulted in bilateral calcification and atrophy of her amygdala (Tranel and Hyman, 1990; Nahm et al., 1993; Adolphs et al., 1994).

Unilateral amygdala lesions. The six subjects in this group had unilateral damage to the amygdala and to other cortical and subcortical regions in the anterior temporal lobe, caused by either temporal lobectomy for the treatment of epilepsy, or by herpes simplex encephalitis.

Brain-damaged controls. Twelve subjects with lesions that did not include the amygdala were selected to address a number of possibly confounding variables.

To conclude that a target subject might be impaired in processing facial expressions of emotion, we needed to exclude the possibility that defective task performance could be attributed solely to confounding variables that could also affect performance on our tasks. These variables included IQ and visuoperceptual function. Our 12 brain-damaged controls, consequently, included subjects with IQ similar to, or lower than, that of subjects with amygdala damage. We addressed the possibility of an effect due to the visuoperceptual demands of the task by including brain-damaged controls who had poor visual acuity or visual field defects, and who performed at or below the level of target subjects on standard tests of visuoperceptual function. To control for the bilaterality of brain damage of SM-046 we included four control subjects with bilateral brain damage. All 12 subjects had participated as controls in a previous study of the recognition of emotion in facial expressions (Adolphs et al., 1994), and included patients with histories of stroke, tumor, or anoxia.

Normal controls. Seven normal controls, with no history of neurological and psychiatric disease, were also included in our study, in order to provide an independent, normal group to which results from subjects in other groups could be compared.

\section{Experimental tasks}

Recognition of facial expressions of emotion. Subjects were shown black and white slides of facial expressions, and were asked to judge the expressions with respect to several verbal labels (which were the adjectives that corresponded to the emotions we showed), as reported previously (Adolphs et al., 1994). We chose 39 facial expressions from Ekman and Friesen (Ekman, 1976) that had all been shown to be identified reliably by normal subjects at greater than $80 \%$ success rate. Each of the 39 expressions was presented six times in two blocks separated by several hours. Six faces (both male and female) each of anger, fear, happiness, surprise, sadness, disgust, and three neutral faces, were projected on a screen, one at a time, in randomized order. Subjects had in front of them cards with verbal labels describing emotions typed in large print, of which they were periodically reminded by the experimenter. Prior to rating faces on any label, subjects were involved in a brief discussion that clarified the meaning of that word through examples. Subjects were asked to judge each face on a scale of $0-5(0=$ not at all; 5 = very much) on the following six labels: happy, sad, disgusted, angry, afraid, surprised (one adjective per block of slides), in random order. There was no time limit. Care was taken to ensure that all subjects knew which label they were rating and used the scale correctly. All subjects understood the labels, as assessed by their ability to describe appropriately scenarios pertaining to that emotional label.

SM-046 repeated the experiment a total of four times, in two sessions 6 months apart. In both sessions, she was tested by different experimenters who were blind to the nature of the experiment, and by R.A. We also replicated the experiments with six of the brain-damaged controls (data not shown), all of whom gave very consistent intrasubject ratings.

Data from the task above were analyzed to yield three measures: (1) subjects' ratings of a facial expression on the verbal label that corresponded to the emotion expressed. This measure is an index of the intensity with which subjects judge a prototypical emotion to be expressed. (2) Correlations between a subject's ratings of an expression and normal ratings. This is a measure of recognition of facial expressions of emotion (Adolphs et al., 1994). A subject's ratings of a facial expression on the six adjectives were correlated with mean ratings of that expression given by the seven normal controls. The correlations were $\mathrm{Z}$-transformed to normalize their distribution, averaged over faces that expressed the same emotion, and inverse $Z$-transformed to give the mean Pearson correlation to normal ratings for that emotion category. (3) Profile of ratings on all six emotional labels for each of the 39 individual facial expressions. An analysis of the raw ratings given by subjects allowed us to investigate further those aspects of task performance that may have resulted in defective recognition. Details are provided in the legend to Figure 5.

Recognition of identity of a face. We also assessed subjects' ability to recognize and name familiar faces, to provide further evidence that recognition of the identity and of the emotion expressed by a face are dissociable (Damasio et al., 1990). Subjects were shown black and white slides of faces that were cropped to include only the head. Stimuli consisted of faces of famous public figures, or of acquaintances of the patient. The scores from these tests are presented as "impaired," "borderline," or "normal," as previously described (Tranel et al., in press).

Drawing facial expressions. The tasks described above do not exhaust in any way the characterization of the defect in recognizing fear in facial expressions. To begin further inquiry on this issue, we carried out additional, qualitative studies with patient SM-046.

To assess SM-046's ability to retrieve nonverbal information pertinent to fear, we asked her, as well as four of our subjects with unilateral amygdala lesions and four control subjects, to draw pictures of facial expressions from memory, given both the oral and written command. She was given unlimited time and was repeatedly prompted by the experimenter. SM-046 had taken a correspondence art class in drawing, and enjoyed drawing.

The verbal concept of fear. Interviews were conducted to address whether SM-046's defect extends to defective conceptual knowledge of fear. Her recognition of the meaning of words that denote emotional states was assessed by asking her to sort printed labels of the words into piles on the basis of the similarity of the emotion they denote.

\section{Results}

Neuroanatomical profiles

MR scans of the subjects with amygdala damage are shown in Figures 1 and 2. Subject SM-046 had damage that was restricted to the amygdala, and which may have included some of the very anterior entorhinal cortex, sparing hippocampus and all neocortical regions (Fig. 1). All of neocortex and the hippocampi are spared, thus providing a particularly specific case study with selective amygdala lesions. PET scans confirmed that the tissue of the amygdala was hypometabolic, consistent with atrophy of this structure (data not shown).

Our subjects with unilateral amygdala damage included temporal lobectomy cases and two subjects with limited damage from herpes simplex encephalitis (LDV-692 and FR-1465). The 
subjects all had unilateral damage to the amygdala and to some of the surrounding structures in the temporal lobe (Fig. 2).

\section{Neuropsychological profiles}

SM-046 is fully dextrous, has an IQ in the low average range, and a high school education. She has intact visual fields and normal acuity, can read and write fluently, and has normal color perception. She has no impairments of memory, language, or perception, with the possible exception of somewhat impaired immediate nonverbal memory (Tranel and Hyman, 1990) and borderline olfactory recognition.

The ability of SM-046 to match simple stimuli across different sensory modalities, as evidenced by visual-tactile associations of simple geometric shapes, is normal (Nahm et al., 1993). SM046 has an inadequate ability to make decisions in regard to personal and social matters, and has somewhat inappropriate social behavior (Tranel and Hyman, 1990; Nahm et al., 1993).

Our subjects with unilateral amygdala damage are all fully dextrous, and include patients with a large range of IQ. All target subjects had normal, or corrected to normal, visual acuity, and none had visual field defects. Table 1 summarizes these data.

\section{Judgments of intensity of emotional facial expressions}

We first examined the intensity of emotion that subjects judged to be signalled by a face. For each face within an emotion category, subjects rated that face on its prototypical verbal label (e.g., for happy faces, "how happy does this person look?"), on a 6-point scale. Brain-damaged and normal controls, as well as subjects with unilateral amygdala lesions all endorsed high ratings on this task across every emotion category (Fig. 3a), indicating that the expressions were, indeed, strong, typical expressions of their respective emotions. There were no significant differences between the ratings given by brain-damaged controls, normal controls, or subjects with unilateral amygdala damage. While all subjects with left amygdala lesions rated faces showing disgust or sadness as slightly less intense than did subjects with right amygdala lesions $(p=0.05$ for both emotions; Mann-Whitney $U$ test), we do not think this finding is significant for our study, since all six subjects' ratings fell within the range of ratings given by brain-damaged controls. Future studies, with planned comparisons between larger numbers of unilaterally lesioned subjects, might follow up this finding in relation to possible hemispheric asymmetries in processing emotion, as has been suggested for other brain regions (e.g., Davidson, 1992).

Our subject with bilateral amygdala damage, SM-046, judged faces showing fear to be less intense expressions of that emotion than did any of the brain-damaged controls, or than did any of the subjects with unilateral amygdala damage (Fig. 3b). SM-046 also differed from brain-damaged controls in her judgments of faces expressing emotions normally judged to be similar to fear: she judged surprised and angry faces to signal less surprise or anger than did controls. Her average ratings of surprise and fear were $5 \mathrm{SD}$ below the mean of the brain-damaged controls' ratings; her ratings of anger were 3 SD below the control mean, and her ratings of all other emotions were within $1 \mathrm{SD}$ of the control mean. These results suggest that bilateral, but not unilateral, damage to the amygdala impairs judgments of the intensity of expressions of fear, and of expressions normally judged to be very similar to fear, such as surprise.
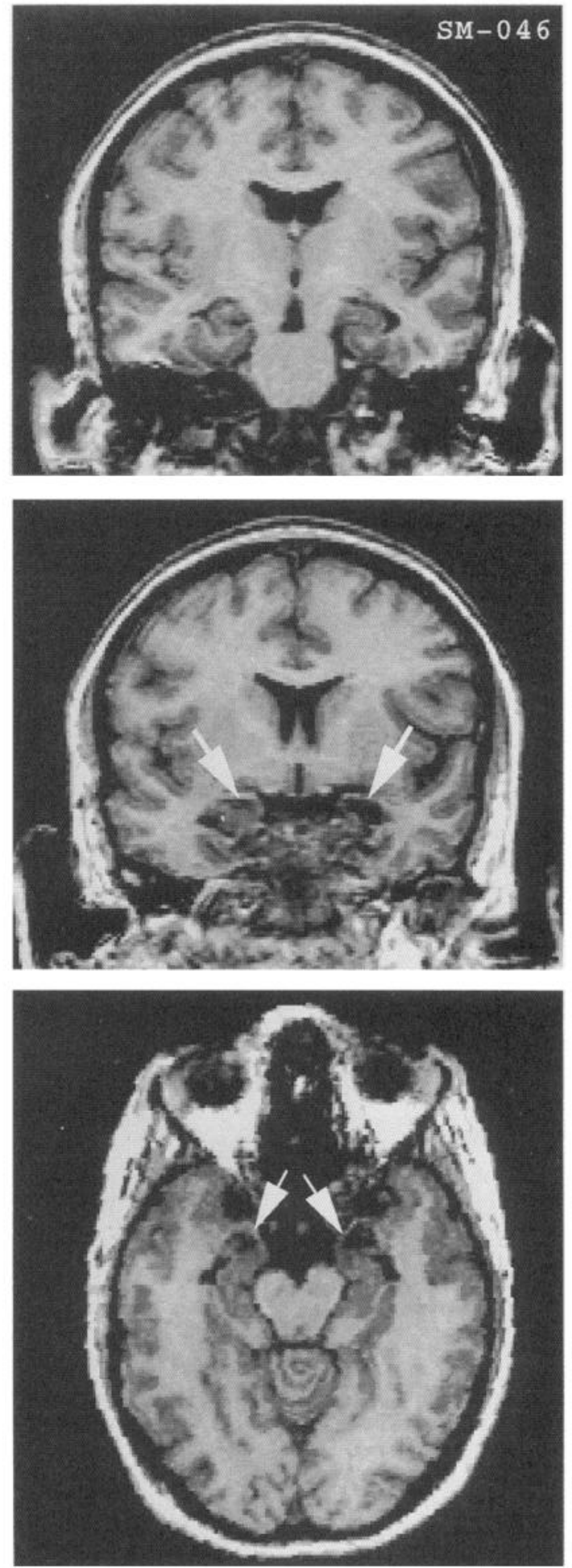

Figure 1. MR scans of the brain of SM-046. From top to bottom: coronal section at the level of the hippocampus; coronal section at the level of the amygdala; horizontal section at the level of the amygdala. SM-046 has extensive and bilateral damage to the amygdala (arrows), but not to other structures, such as the hippocampus (top).

\section{Recognition of emotional facial expressions}

To assess recognition of facial expressions, we asked subjects to rate the face not just on the verbal label that described it best, but also on labels denoting other emotions. The rationale for this 


\section{A.}
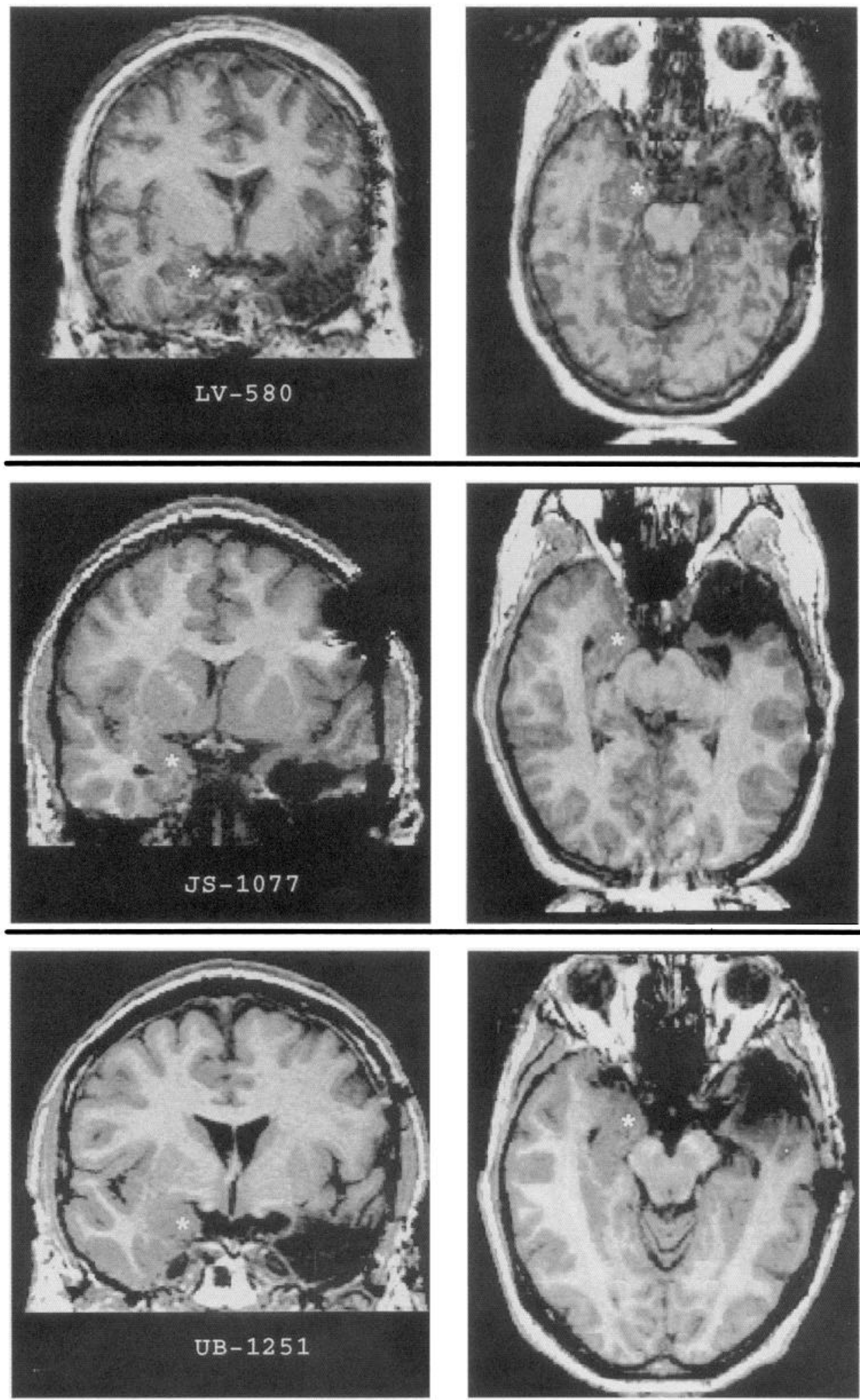

Figure 2. Sites of lesions of subjects with unilateral amygdala damage. $A$, Subjects with left amygdala lesions. $B$, Subjects with right amygdala lesions. For each subject, coronal and horizontal sections at the level of the amygdala are shown at left and right, respectively. The intact amygdala on one side is indicated with an asterisk. Note that the left side of the image corresponds to the right side of the brain, and vice versa.

typical facial expression of surprise, and yet also be judged to exhibit some happiness, or some fear. Asking subjects to apply a single label to a facial expression will thus not be a complete index of all the information recognized, and is not a sensitive test of recognition of emotion. method came from previous studies with normal subjects, which showed that facial expressions signal more than one emotion, and that emotion categories have fuzzy and overlapping boundaries (Russell and Bullock, 1986; Russell and Fehr, 1987; Russell, 1991). For example, a surprised person can have a proto- 
B .
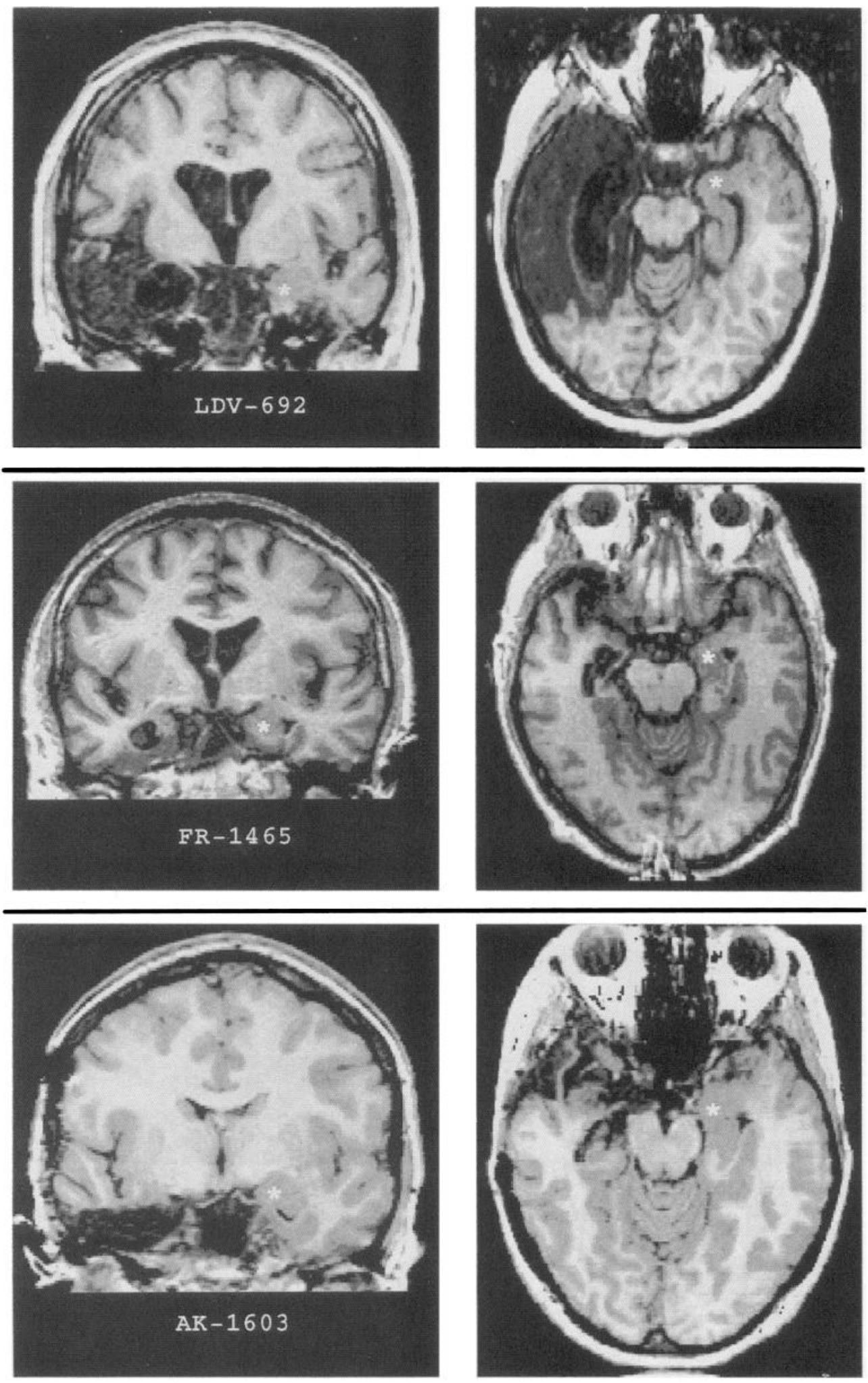

Figure 2. Continued.

Brain-damaged controls and subjects with unilateral amygdala damage gave ratings of the faces that correlated well with normal ratings (Fig. 4). Our subject with bilateral amygdala damage, by contrast, had a severe impairment in the ability to recognize some expressions, as assessed by this task. SM-046 en- dorsed ratings for afraid faces that correlated very poorly, or not at all, with normal ratings, and which correlated more poorly with normal ratings than did the ratings given by any braindamaged control (Fig. 4).

These data show that bilateral, but not unilateral, damage to 
Table 1. Background neuropsychology of subjects

\begin{tabular}{|c|c|c|c|c|c|}
\hline \multirow[b]{2}{*}{ Subject } & \multirow[b]{2}{*}{ Age/sex } & \multirow[b]{2}{*}{ VIQ } & \multirow[b]{2}{*}{ PIQ } & \multicolumn{2}{|c|}{$\begin{array}{l}\text { Visuoperceptual } \\
\text { function (\% } \% \text { ile) }\end{array}$} \\
\hline & & & & Lines & Faces \\
\hline \multicolumn{6}{|c|}{ Bilateral amygdala damage } \\
\hline SM-046 & $30 / \mathrm{F}$ & 86 & 90 & 11 th & 90th \\
\hline \multicolumn{6}{|c|}{ Left amygdala damage } \\
\hline LV-580 & $31 / \mathrm{F}$ & 81 & 112 & 40th & 49th \\
\hline JS-1077 & $22 / \mathrm{M}$ & 129 & 126 & 74th & 8th \\
\hline UB-1251 & $35 / \mathrm{M}$ & 93 & 99 & $22 n d$ & 49th \\
\hline \multicolumn{6}{|c|}{ Right amygdala damage } \\
\hline LDV-692 & $31 / \mathrm{F}$ & 87 & 77 & 11 th & 4th \\
\hline FR-1465 & $64 / \mathrm{M}$ & 100 & 130 & $72 \mathrm{nd}$ & 77 th \\
\hline AK-1603 & $25 / \mathrm{F}$ & 106 & 133 & 56 th & $32 \mathrm{nd}$ \\
\hline \multicolumn{6}{|c|}{ Brain-damaged controls } \\
\hline CE-1023 & $68 / \mathrm{M}$ & 117 & 96 & 40 th & 6th \\
\hline WW-1257 & $73 / \mathrm{M}$ & 117 & 93 & 86 th & 97th \\
\hline RM-1362 & $68 / \mathrm{M}$ & 96 & 110 & 86 th & 15 th \\
\hline RJ-1374 ${ }^{a}$ & $52 / \mathrm{M}$ & 96 & 96 & NT & $71 \mathrm{st}$ \\
\hline JR-1584 & $51 / \mathrm{M}$ & 90 & 111 & 99 th & 49 th \\
\hline RJ-1605 & $49 / \mathrm{M}$ & $114^{b}$ & $112^{b}$ & NT & 15 th \\
\hline DE-1607 & $77 / \mathrm{F}$ & 98 & 90 & 22nd & 49 th \\
\hline$\underline{\mathrm{RS}-1658}$ & $49 / \mathrm{M}$ & 101 & 82 & 4th & $71 \mathrm{st}$ \\
\hline $\mathrm{BL}-1722^{d}$ & $52 / \mathrm{F}$ & 85 & 85 & Oth & 49th \\
\hline$\underline{\text { RM-1740 }}$ & $63 / \mathrm{M}$ & 94 & 101 & NT & NT \\
\hline MR-1790 & $62 / F$ & 97 & 80 & 56 th & 77th \\
\hline CF-1899a & $64 / \mathrm{M}$ & 120 & 115 & $56 \mathrm{th}$ & $71 \mathrm{st}$ \\
\hline
\end{tabular}

VIQ, PIQ: verbal and performance IQs from the Wechsler Adult Intelligence Test-Revised (WAIS-R) (Wechsler, 1981). Lines: ability to discriminate between orientation of lines (Benton et al., 1983). Faces: ability to discriminate between similar faces (Benton et al., 1983). Underlined subjects have bilateral lesions. NT: Not tested.

"Blind in one visual field.

${ }^{b}$ Estimated from the National Adult Test-Revised.

- Perimetric mapping indicated complete blindness in the left visual field, and macular sparing not extending past $10^{\circ}$ eccentricity in the right visual field.

"Nearly blind in left eye; achromatopsic.

the amygdala impairs the processing of some facial expressions of emotion. The recognition of fear appears to be most severely impaired.

\section{Recognition of multiple emotion categories}

The impaired recognition of expressions of fear seen in SM-046 could have several causes at the level of task performance. She might not know what fearful faces signal at all, or she might misrecognize fear as another emotion. To address this issue, we analyzed each facial expression's membership in different emotion categories. Figure 5 shows the ratings given by subjects for all the faces, on all the different adjectives that describe emotions. Controls show peaks in their rating profiles that coincide with the facial expression most typical of that adjective: happy faces received the highest ratings on "happy," sad faces on "sad," and so on. Several important points emerge from the data of the controls (both brain-damaged and normal controls): (1) there are prototypical expressions that best exemplify an emotion, (2) most faces belong largely to one emotion category, (3) most faces also have some membership in other categories of emotions that are judged to be similar, (4) most faces therefore signal multiple emo-
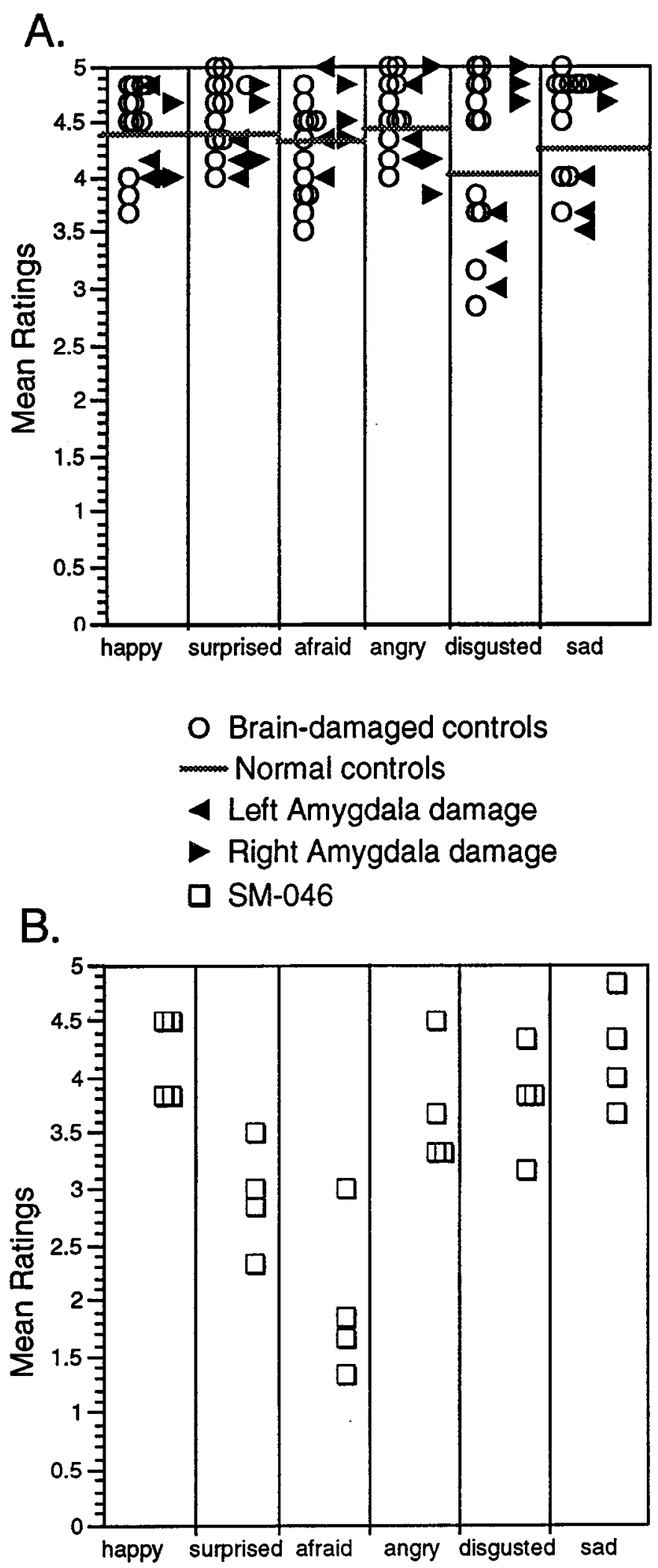

Figure 3. Ratings of the intensity of an emotion in facial expressions. Rating scores (from 0-5) on the emotional word for which the face was a typical example are shown as the mean of all faces within an emotion category. $A$, Data from 12 brain-damaged controls $(O), 3$ subjects with left $(\checkmark)$, and 3 with right $(\square)$ amygdala damage. $B$, Mean data from four experiments with SM-046 ( $\square$ ). 


\section{Right Amygdala

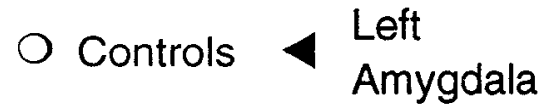

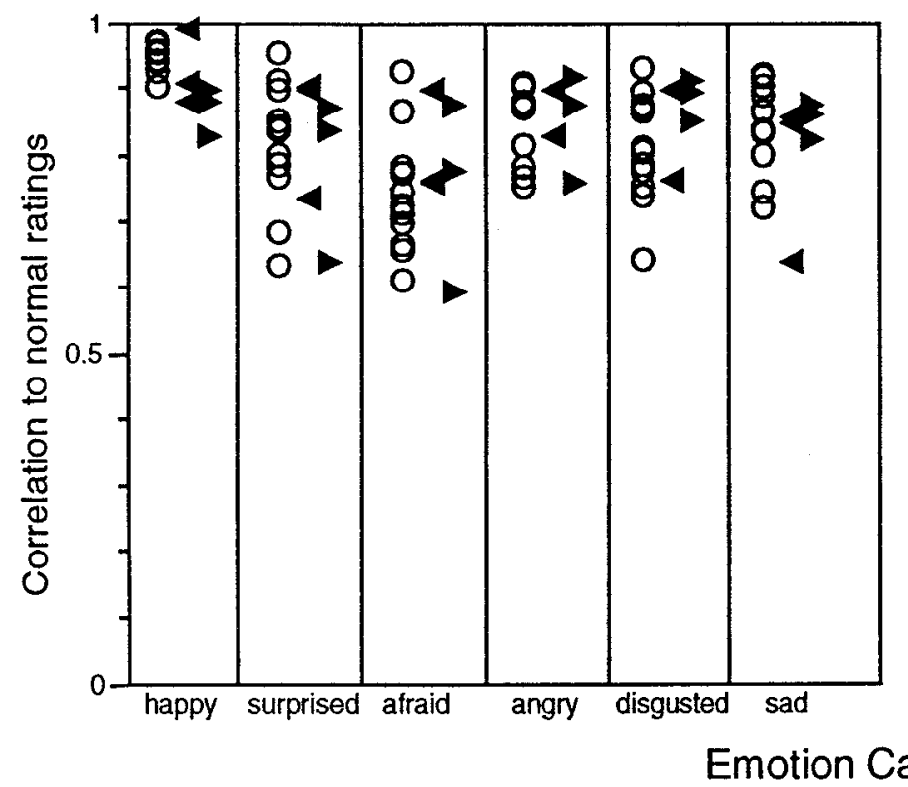

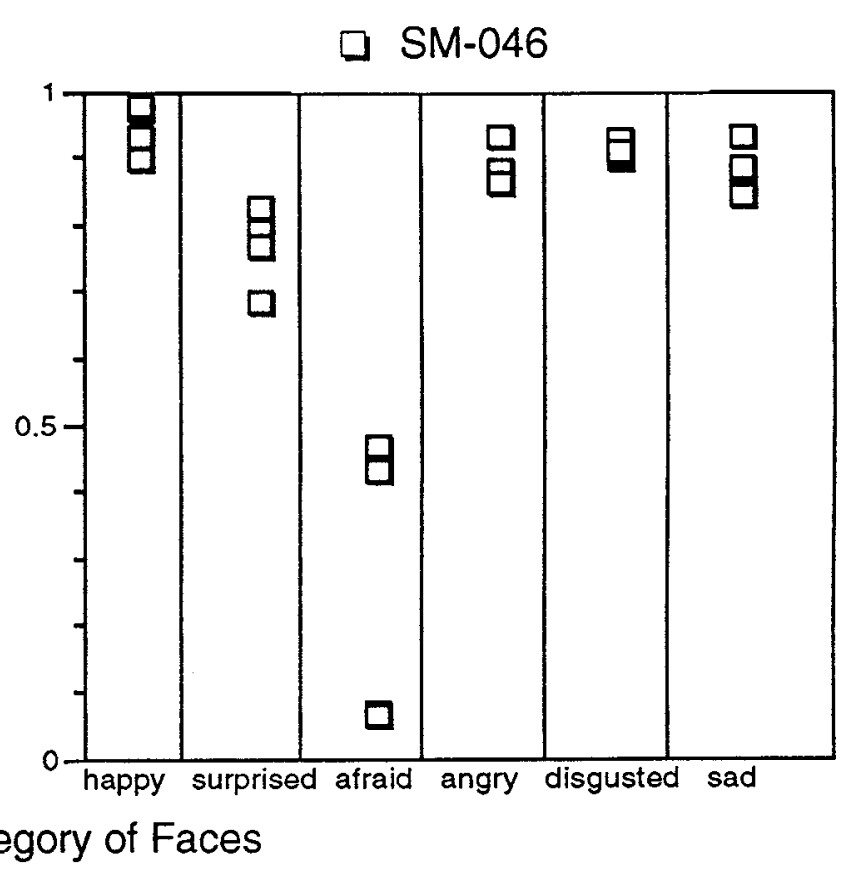

Figure 4. Correlations of subjects' ratings with normal ratings. Mean Pearson correlations are shown of mean normal control ratings $(n=7)$ correlated with the ratings given by brain-damaged controls $(O ;) n=12$, by subjects with left amygdala lesions $(4 ; n=3)$, and subjects with right amygdala lesions $(\square ; n=3$ ) (left), and correlated with the ratings given by SM-046 ( $\square$; four experiments) (right). All normal controls' ratings correlated well with one another $(r>0.7$ for every emotion category).

tions. These observations have been made in previous studies of normal subjects (e.g., Russell and Bullock, 1986).

Normal controls, brain-damaged controls, and patients with unilateral amygdala damage yiclded similar data in this analysis. However, SM-046 differed from all other subjects in the ratings she assigned to some faces (Fig. 5). SM-046 failed to assign high ratings of fear to faces that controls judge to depict fear. She also failed to assign normal ratings of fear or of surprise to faces that are judged similar to fear, such as surprised faces. However, the highest ratings that SM-046 gave on the adjective "afraid" do conrespond to faces expressing fear or surprise. In one session (January) she generally gave such faces higher scores on adjectives denoting emotions other than fear, leading to classification of the expression into an incorrect emotion category. Consequently, SM-046 often described faces depicting fear as surprised or angry. In another session (July), she did not give fearful faces high ratings on any emotion label (Fig. 5).

We followed up this experiment by asking SM-046 explicitly to comment in more detail about those fearful facial expressions that she had been unable to recognize, and that she had rated as not being afraid. Although she could recognize that an emotion was being expressed (she did not think they were neutral), she was unsure of what the emotion might be, supplying answers that included surprise, anger, disgust, sadness, and, on some occassions, fear.

Given these data, and the further finding that SM-046 never attributed a clearly absent emotion to faces expressing fear (she never called them happy, for instance), we think that the primary defect in SM-046 consists in a specific insensitivity to the emotion of fear in facial expressions, with intact recognition of all other emotions.

\section{Double dissociation between recognition of identity and expression}

SM-046 had no difficulty recognizing people by their faces. She correctly identified 19 of 19 acquaintances (Adolphs et al., 1994), and learned the identity of new faces with ease (Table 2). She also performed normally in discriminating similar faces from one another (Tranel and Hyman, 1990; see Table 1).

Several of the patients with unilateral amygdala lesions had difficulty in naming familiar faces, which we have previously attributed to damage to anterior temporal cortices (Damasio et al., 1990). The two patients with the most extensive lesions of the temporal lobe (LDV-692 and FR-1465) were also significantly impaired in recognizing the identity of faces (Table 2 ).

These data provide additional evidence for a double dissociation (cf. McCarthy and Warrington, 1990, pp 17-19) between recognition of emotion and of identity in faces: while SM 046 is impaired at recognizing some emotional facial expressions, but not facial identity, two of our other subjects, LDV-692 and FR-1465, were impaired at recognizing facial identity (cf. Tranel et al., 1988, patient \#2), but not emotion in facial expressions. These results are consistent with previous findings that recognition of facial identity can be impaired while sparing recognition of the emotion signalled by a face (Tranel et al., 1988; Damasio et al., 1990; Humphreys et al., 1993). 

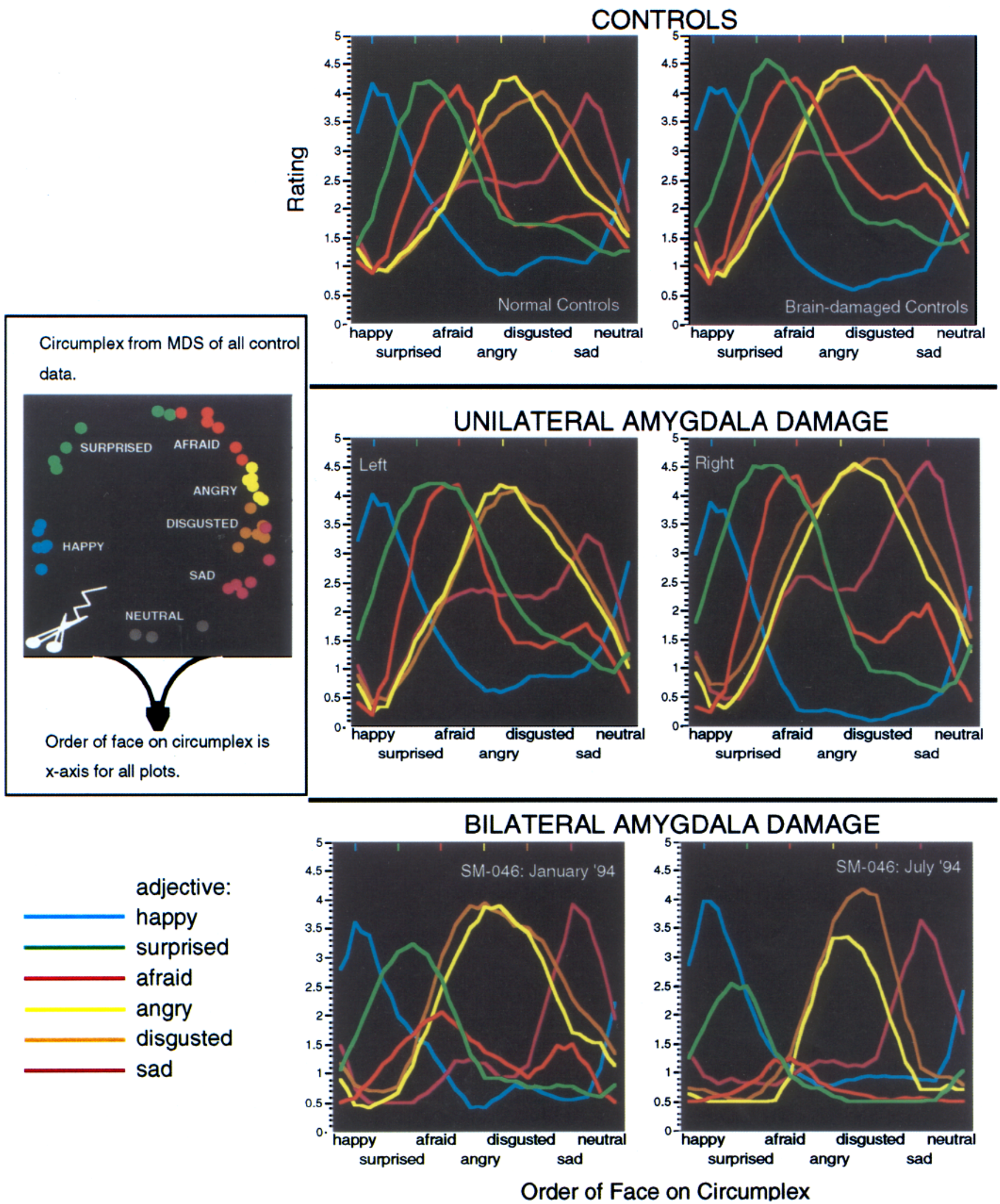

Figure 5. Rating facial expressions with different emotional adjectives. Each plot shows the mean ratings from each group of subjects, or from two experiments with SM-046. Position on the x-axis represents a specific face, such that adjacent positions represent expressions judged to be most similar by controls. To derive the order of faces along the $\mathrm{x}$-axis, we employed a multidimensional scaling technique on the correlations of each face's ratings with one another (see Adolphs et al., 1994, for details). This multidimensional scaling solution for control subjects, shown as the inset to the left, depicts perceived similarity of faces by their Euclidean proximity. We cut this circular arrangement at the indicated position, and mapped the serial order of all 39 faces onto the x-axes of each plot. Consequently, the faces at the origin, and at the extreme right of the $x$ axis (happy and neutral faces), are, in fact, similar, since the scale wraps around the x-axis. The center of each group of faces within an emotion 


\begin{tabular}{lll}
\hline \multicolumn{2}{l}{ Table 2. } & Recognition and naming of familiar faces \\
Subject & Recognition & Naming \\
\hline Bilateral amygdala damage & \\
SM-046 & normal & normal \\
Left amygdala damage & & \\
LV-580 & normal & impaired \\
JS-1077 & normal & normal \\
UB-1251 & normal & impaired \\
Right amygdala damage & & \\
LDV-692 & impaired & impaired \\
FR-1465 & impaired & impaired \\
AK-1603 & normal & normal \\
Brain-damaged controls & & \\
CE-1023 & normal & normal \\
WW-1257 & normal & normal \\
RM-1362 & normal & borderline \\
RJ-1374 & normal & normal \\
JR-1584 & normal & normal \\
RJ-1605 & normal & normal \\
DE-1607 & normal & normal \\
RS-1658 & normal & normal \\
BL-1722 & normal & normal \\
MM-1740 & normal & NT \\
CF-1899 & normal \\
\hline & normal \\
\hline
\end{tabular}

\section{Drawing facial expressions}

We now describe the results of more qualitative experiments, which are intended to supplement the above data. Might SM046's impairment be limited to recognition, or might she have a more general impairment in memory for stimuli with emotional meaning? This question is especially important, as recent evidence suggests that there are double dissociations between impairments of visual perception and impairments of visual imagery (Behrmann et al., 1992; Guariglia et al., 1993).

To assess the ability of SM-046 to construct an image of an afraid face, we asked her and eight other subjects to draw pictures of facial expressions from memory. This task was administered immediately after subjects had been exposed to all the pictures of facial expressions used in our other experiments. They thus had significant exposure to facial expressions just prior to the drawing session.

Subjects vary widely in their ability to draw facial expressions. However, all subjects that were able to draw disgusted or angry faces, or able to draw faces in the detail that SM-046 did, were able to draw clear facial expressions of fear. All patients with unilateral amygdala damage that we tested on this task $(n=4)$ were able to draw facial expressions of fear, although many sub- jects found fear, anger, and disgust more difficult expressions to draw.

SM-046's drawings are reproduced in Figure 6. SM-046 was able to produce without difficulty skillful renditions of all facial expressions except fear. She often provided additional context, and enjoyed drawing. However, she was entirely unable to draw expressions of fear. She explained that she did not know what an afraid face would look like, and that she was unable to draw any depiction of it. The experimenter had to prompt repeatedly to elicit any kind of drawing of fcar at all; she produced her drawing only after several failed attempts. She knew, however, that people who are afraid will tend to cower, and are typically portrayed with their hair standing on end, two features that did find their way into her drawing (Fig. 6). But she could not bring to mind any image of a facial expression to go with fear, and, accordingly, this was the only one of her six drawings that did not include a frontal view of the face.

\section{The concept of fear}

The above results might suggest that SM-046 simply lacks the concept of fear, and thus cannot evoke this concept when she encounters a facial expression that denotes it. However, our interviews with her revealed that she does know (a) what sorts of situations would evoke fear in people (being threalened, being alone in a dark alley at night, and so on), and (b) how frightened people tend to behave (their heart pounds, they may scream, and they try to run away). During the course of extensive interviews, SM-046 used the words, "fear," "afraid," "frightened," appropriately.

We further tested SM-046's ability to recognize the meaning of words denoting emotions by her ability to sort a set of 28 adjective labels into various numbers of piles on the basis of the similarity of the cmotion denoted by an adjective. She performed normally on this task, and grouped together the words, "afraid," "scared," "worried," "terrified," and "alarmed," indicating that she found them to be closely related.

We have no way of testing for all components of the concept of fear in SM-046. It does appear that she can access many important components of the concept, provided that they admit of verbal description. We think it likely, however, that SM-046 does not experience fear in a normal way, as we have found no convincing evidence that she feels frightened given the appropriate stimulus, and have preliminary evidence that she fails to exhibit the full range of psychophysiological responses to fear (A. Bechara, R. Adolphs, D. Tranel, personal observation). This issue requires additional studies, some of which are now underway.

\section{Discussion}

Based on a series of quantitative tasks, we have shown that bilateral amygdala damage (1) impairs judgments of the intensity of faces depicting fear, (2) impairs judgments of faces depicting fear with respect to several emotional labels, (3) impairs the ability to detect fear in faces predominantly depicting other ex-

category is denoted on each plot by the colored bar at the very top of the graph. The y-axis represents the mean rating (from 0-5) given to a facial expression. Each of the differently colored lines corresponds to the ratings endorsed on a particular emotional label. For ease of visualization, all plots were smoothed as follows. We triplicated the summed raw data for each plot, producing three plots strung together, in order to embed the center plot in continuous data, and applied a Lowess smoothing filter with a 5\% window. The center plot of the three plots was used, and numbers were divided by the number of datasets to produce the final plot shown on the figure. Careful comparisons with the raw data confirmed that the smoothing procedure conservatively captured the relevant trends in the data without producing artifacts. Top: data from brain-damaged ( $n-12$ ) and normal controls $(n=7)$. Middle: data from subjects with left $(n=3)$ and right $(n=3)$ unilateral amygdala damage. Bottom: data from subject with bilateral amygdala damage. Each of the two plots for SM-046 correspond to the mean of two experiments. 


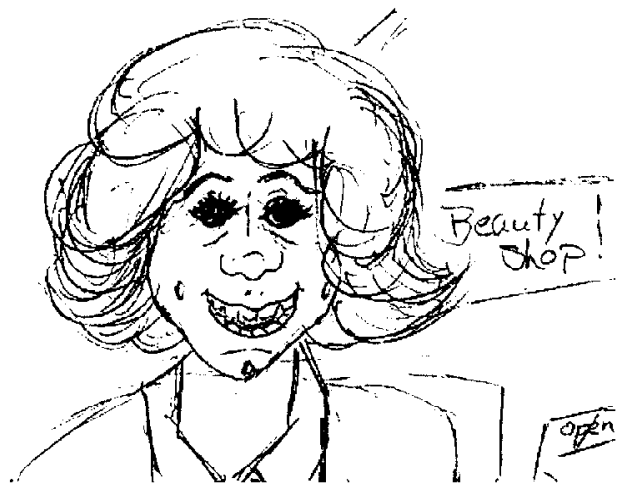

HAPPY

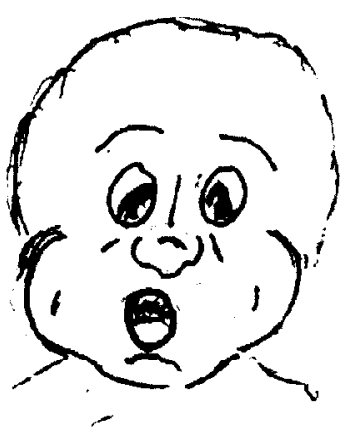

SURPRISED

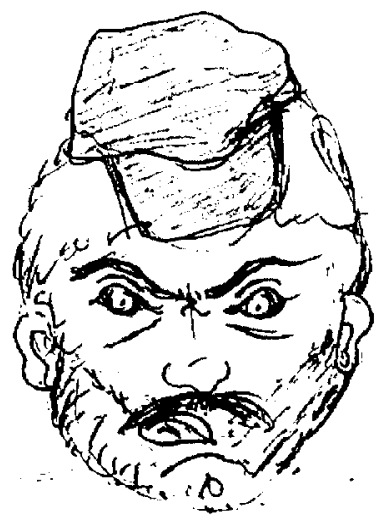

ANGRY

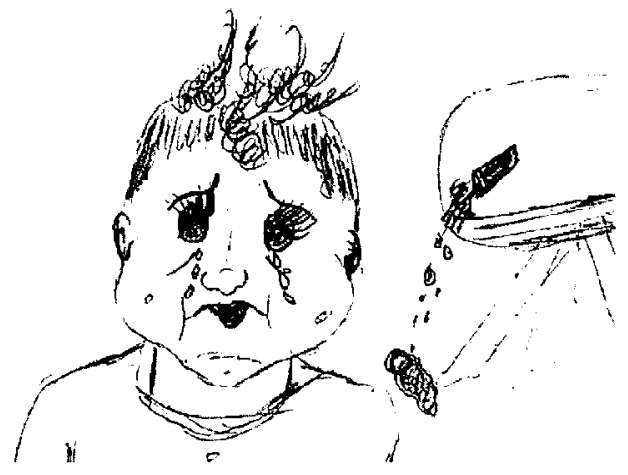

SAD

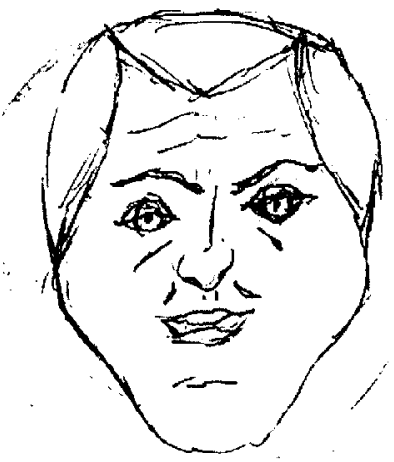

DISGUSTED

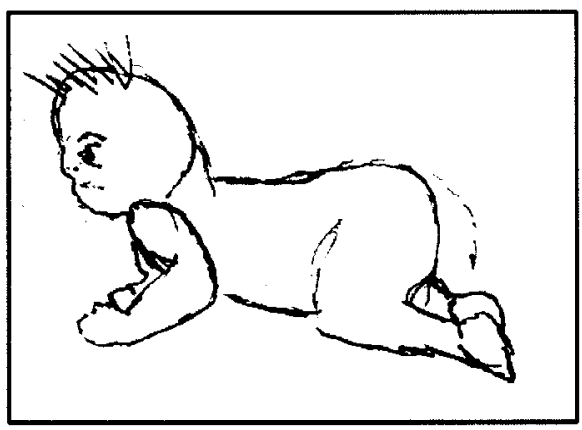

AFRAID

Figure 6. SM-046's drawings of facial expressions from memory. SM-046 tended to provide context to her drawings, in all cases appropriate. She insisted that she did not know how to draw an afraid face, because she did not know what such an expression would look like. Her drawing was produced only after repeated prompting, and she was not satisfied with it.

pressions (such as surprise), and (4) leaves intact the ability to recognize the identity of faces. In addition, based on supplementary, qualitative tasks, we suggest that bilateral amygdala damage compromises the ability to reconstruct visual images of faces that depict fear, while leaving intact many aspects of the concept of fear that can be verbally described. None of the subjects with unilateral amygdala damage were impaired at recognizing any facial expressions.

Taken as a whole, these results suggest that bilatcral amygdala damage impairs the processing of facial expressions of fear both in recognition and in recall. However, the full scope of the impairments that follow bilateral damage to the human amygdala will be broader than what we have reported here. For example, it is likely that behaviors that depend on recognition of facial expressions, such as components of social behavior, are also compromised in some way.

One important issue is the age of subjects at the onset of their amygdala damage: all patients with unilateral amygdala damage sustaincd damagc to this structure in late adolescence or in adulthood. They would thus have had many years with bilaterally 
intact amygdalae prior to sustaining their lesion. It is somewhat less clear at what point in time SM-046 acquired her amygdala lesions. We cannot reconstruct the time course of SM-046's lesions with any certainty. However, the literature on Urbach-Wiethe disease (Hofer, 1973), together with reports of SM-046's childhood, suggest that the neurological symptoms that can result from this disease are progressively acquired throughout late childhood and adolescence, as calcified material continues to be deposited in the tissue and blood vessels of mesial temporal structures. We thus consider it likely that all our patients with amygdala lesions acquired such lesions several years into their life, and had occasion to develop an initially normal concept of fear prior to the onset of their lesion.

\section{Studies of the amygdala in humans}

Studies of the amygdala in humans have come largely from two sources: surgical lesions and electrical stimulation. Although surgical lesions of the human amygdala suffer from the drawback that they may be incomplete, and that the subjects may not be normal prior to the surgery (Narabayashi, 1972; Jacobson, 1986; Lee et al., 1988a,b), a review of these cases (Aggleton, 1992) strongly supports the role of the amygdala in processing fear and aggression and in social behavior. Electrical stimulation studies of the amygdala in epileptic patients also suffer from comparable drawbacks, but are again suggestive of functions related to fear, aggression, and social behavior (Chapman et al., 1954; Heath et al., 1955; Halgren et al., 1978; Gloor et al., 1982).

Our subject SM-046 provides a rare opportunity to examine selective and bilateral lesions of the amygdala in humans. A recent report of two other patients with Urbach-Wiethe disease suggested that they were impaired in processing information that had emotional significance (Markowitsch et al., 1994). Functional imaging studies with PET in these patients (Markowitsch et al., 1994), as well as in SM-046, confirmed that the amygdala is severely hypometabolic, as would be expected of atrophic tissue.

\section{The amygdala is an essential link in the response to stimuli with emotional value}

In primates, the amygdala projects back to all visual cortices, including the striate cortex (Amaral and Price, 1984; Iwai and Yukie, 1987; Amaral et al., 1992). It is thus possible that highlevel feedback from the amygdala directly participates in the activity of those regions, during both perception (Rolls, 1992) and visual imagery (Damasio et al., 1993; Kosslyn et al., 1993). We envision the function of the human amygdala as a high-order "convergence" zone for the social, homeostatic, and survivalrelated meaning of a class of complex stimuli, such as facial expressions of some emotions (Damasio, 1989; Damasio and Damasio, 1993; Damasio, 1994). In this view, to recognize someone as afraid, the amygdala must make the sight of the fearful face activate myriad cortical and subcortical regions, whose ensemble, temporally coordinated activity constitutes the concept of fear. Important components of such a distributed, macroscopic neural representation would result from the amygdala's engagement of limbic and somatic activity during danger or threat, and from the engagement of sensory cortices that represent entities and scenarios related to fear. The amygdala may thus orchestrate patterns of neural activation in disparate sectors of the brain that would encode both the intrinsic, physical features of stimuli (e.g., shape, position in space, and so on), and the value that certain stimuli have to the organism (e.g., their emotional significance).

We propose that SM-046 can perceive the visual features of a face normally; i.e., she constructs normal percepts of the physical features of a face. She can also connect such percepts with the class of knowledge necessary to identify a familiar person: the sight of a familiar face activates internal responses that subsume knowledge pertinent and specific to that unique face. How ever, she lacks the ability to link the perception of certain constellations of facial features to the class of knowledge related to emotions, specifically to the knowledge of fear: the perception of an expression of fear fails to activate responses that subsume the concept of fear (these responses would include autonomic changes, changes in posture, and facial expression of SM-046, mental images describing scenarios related to fear, verbal reports pertaining to the fearful face, etc.). The broken link in SM-046 affects a bidirectional process: she cannot retrieve knowledge about fearful faces when confronted with the face, and she also cannot generate constellations of the facial features of fear in imagery when given the verbal label.

When SM-046 fails to recognize fear in facial expressions, what does she think those expressions are? SM-046 sometimes described faces denoting fear as looking surprised or angry, behavior exhibited also by normal subjects to some degree. Rarely, she would even describe a face as looking afraid, but always insisted that it was not very afraid. In several experiments, she appeared to have no idea what emotion was being signalled by an afraid face, and gave the face the lowest possible ratings on all emotion labels. Our interpretation is that SM-046 did not think afraid faces looked as afraid as the controls thought they did. However, since she was able to recognize other emotional expressions, she also did not think that afraid faces exhibited an emotion that was not at all present (for instance, she never thought afraid faces looked happy).

Interestingly, SM-046 did give the highest mean ratings on the adjective "afraid" to faces that depicted fear, just as controls did (Fig. 5), but she was quite abnormal in the low magnitude of fear she ascribed to those faces. These results are consistent with our proposal: SM-046 can decide to some extent whether a person may be expressing fear or not, possibly by reasoning from prototypical features she knows to accompany fear (e.g., wide eyes), and possibly reasoning from exclusion of other emotions that she can recognize normally. However, she lacks the ability to link the perception of the expression with knowledge that would allow her to judge the intensity of the emotion. Our proposal, then, is that the amygdala is essential to retrieve comprehensive knowledge related to the conccpt of fear.

Her impaired ability to produce drawings of expressions of fear lend further support to this interpretation. Although SM-046 was able to portray some of the stereotypical features normally associated with the expression of fear (cowering posture, hair standing on end), she was unable to construct an image of a facial expression. This task requires the generation of an image on the basis of its link to a verbal label denoting a concept. We propose that the ability to link representations of facial expressions of fear to other components of the concept of fear is bidirectionally defective in SM-046.

\section{The amygdala and social behavior}

The behavioral impairments of amygdalectomized monkeys are most severe in the wild, resulting in the death of the animal if left unattended in its troop (Kling and Brothers, 1992). Neurons 
within the amygdala are active during social interactions (Kling et al., 1979) and social communication (Jurgens, 1982). The profound social dysfunction of amygdalectomized animals (Rosvold et al., 1954) can be understood in the context of the findings described above. The integration of complex sensory information, such as recognition of faces, with the motivational valence of the stimulus, is especially important in order to recognize social intentions, social status, and to guide belavior on the basis of social cues (threats, warnings, submissive gestures; Kling and Brothers, 1992).

It is noteworthy that the behavior of SM-046, even in real life, is not nearly as impaired as that of monkeys with experimental amygdala lesions. She has a history of inadequate social decision making, somewhat inappropriate behavior, failure to maintain employment or marital relations, and she depends on welfare. Nonetheless, SM-046 is not a social outcast. One reason for the discrepancy between social behavior in amygdalectomized monkeys and in SM-046 might be that the monkeys have more complete lesions, or lesions in structures other than the amygdala. Another reason for the difference may be that the amygdala is less important to social behavior in the case of humans than in the case of monkeys. Humans can engage declarative knowledge and reasoning in a purely verbal mode, which largely parallels the nonverbal processes directly guided by circuits that include the amygdala. Nonetheless, we believe complex social and aesthetic judgments in humans do require all the neural machinery used to process emotions, and certainly do include the amygdala (Damasio, 1994). It is only that the deficits produced by dysfunction in these basic systems may be partially masked by the intact propositional competence of humans, thus making the behavioral sequalae of bilateral human amygdala damage somewhat more subtle.

\section{References}

Adolphs R, Tranel D, Damasio H, Damasio A (1994) Impaired recognition of emotion in facial expressions following bilateral damage to the human amygdala. Nature 372:669-672.

Aggleton JP (1992) The functional effects of amygdala lesions in humans: a comparison with findings from monkeys. In: The amygdala: neurobiological aspects of emotion, memory, and mental dysfunction (Aggleton JP, ed), pp 485-504. New York: Wiley-Liss.

Allison T, McCarthy G, Nobre A, Puce A, Belger A (1994) Human extrastriate visual cortex and the perception of faces, words, numbers, and colors. Cereb Cortex 4:544-554.

Amaral DG, Price JL (1984) Amygdalo-cortical connections in the Inonkey (Macaca fascicularis). J Conn Neurol 230:465-496.

Amaral DG, Price JL, Pitkanen A, Carmichael ST (1992) Anatomical organization of the primate amygdaloid complex. In: The amygdala: neurobiological aspects of emotion, memory, and mental dysfunction (Aggleton JP, ed), pp 1-66. New York: Wiley-Liss.

Behrmann M, Winocur G, Moscovitch M (1992) Dissociation between mental imagery and object recognition in a brain-damaged patient. Nature 359:636-637.

Blanchard DC, Blanchard RJ (1972) Innate and conditioned reactions to threat in rats with amygdaloid lesions. J Comp Physiol Psychol $81: 281-290$.

Bowers D, Heilman KM (1984) Dissociation between the processing of affective and nonaffective faces: a case study. J Clin Neuropsychol $6: 367-379$.

Chapman WP, Schroeder HR, Geyer G, Brazier MAB, Fager C, Poppen JL, Solomon HC, Yakovlev PI (1954) Physiological evidence concerning importance of the amygdaloid nuclear region in the integration of circulatory function and emotion in man. Science 120:949950.

Damasio AR (1989) Time-locked multiregional retroactivation: a systems-level proposal for the neural substrates of recall and recognition. Cognition 33:25-62.
Damasio AR (1994) Descartes' error: emotion, reason, and the human brain. New York: Grosset/Putnam.

Damasio AR, Damasio H (1993) Cortical systems for retrieval of concrete knowledge: the convergence zone framework. In: Large scale neuronal theories of the brain (Koch C, ed). London: MIT Press.

Damasio AR, Tranel D, Damasio H (1990) Face agnosia and the neural substrates of memory. Annu Rev Neurosei 13:89-109.

Damasio H, Damasio AR (1989) Lesion analysis in neuropsychology. New York: Oxford UP.

Damasio H, Frank R (1992) Three-dimensional in vivo mapping of brain lesions in humans. Arch Neurol 49:137-143.

Damasio H, Grabowski TJ, Damasio A, Tranel D, Boles-Ponto L, Watkins GL, Hichwa RD (1993) Visual recall with eyes closed and covered activates early visual cortices. Soc Neurosci Abstr 19:1603.

Darwin C (1872/1965) The expression of the emotions in man and animals. Chicago: University of Chicago.

Davidson RJ (1992) Anterior cerebral asymmetry and the nature of emolion. Brain Cugnil 6:245-268.

Davis M (1992a) The role of the amygdala in conditioned fear. In: The amygdala: neurobiological aspects of emotion, memory, and mental dysfunction (Aggleton JP, ed), pp 255-306. New York: Wiley-Liss.

Davis M (1992b) The role of the amygdala in fear and anxiety. Annu Rev Neurosci 15:353-375.

Ekman P (1976) Pictures of facial affect. Palo Alto, CA: Consulting Psychologists.

Gloor P, Olivier A, Quesney LF, Andermann F, Horowitz S (1982) The role of the limbic system in experiential phenomena of temporal lobe epilepsy. Ann Neurol 12:129-144.

Guariglia C, Padovani A, Pantano P, Pizzamiglio L (1993) Unilateral neglect restricted to visual imagery. Nature 364:235-237.

Halgren E, Walter RD, Cherlow DG, Crandall PH (1978) Mental phenomena evoked by electrical stimulation of the human hippocampal formation and amygdala. Brain 101:83-117.

Hasselmo ME, Rolls ET, Baylis GC (1989) The role of expression and identity in the face-selective responses of neurons in the temporal visual cortex of the monkey. Behav Brain Res 32:203-218.

Heath RG, Russell RM, Mickle WA (1955) Stimulation of the amygdaloid nucleus in a schizophrenic patient. Am J Psychiatry 111:862863.

Heit G, Smith ME, Halgren E (1988) Neural encoding of individual words and faces by the human hippocampus and amygdala. Nature 333:773-775.

Hensman R, Guimaraes FS, Wang M, Deakin JFW (1991) Effects of ritanserin on aversive classical conditioning in humans. Psychopharmacology (Berlin) 104:220-224.)

Herzog AG, Van Hoesen GW (1976) Temporal neocortical afferent connections to the amygdala in the rhesus monkey. Brain Res 115: $57-69$.

Hitchcock JM, Davis M (1986) Lesions of the amygdala, but not of the cerebellum or red nucleus, block conditioned fear as measured with the potentiated startle paradigm. Behav Neurosci 100:11-22.

Hofer P-A (1973) Urbach-Wiethe disease: a review. Acta Derm Venerol 53:5-52.

Humplireys GW, Domelly N, Riddoch MJ (1993) Expression is computed separately from facial identity, and it is computed separately for moving and static faces: neuropsychological evidence. Neuropsychologia 31:173-181.

Iwai E, Yukie M (1987) Amygdalofugal and amygdalopetal connections with modality-specific visual cortical areas in Macaques. J Comp Neurol 261:362-387.

Jacobson R (1986) Disorders of facial recognition, social behavior and affect after combined bilateral amygdalotomy and subcaudate tractotomy-a clinical and experimental study. Psychol Med 16:439-450.

Jurgens U (1982) Amygdalar vocalization pathways in the squirrel monkey, Brain Res 241:189-196.

Kapp BS, Gallagher M, Applegate CD, Frysinger RC (1982) The amygdala central nucleus: contributions to conditioned cardiovascular responding during aversive Pavlovian conditioning in the rabbit. In: Conditioning: representation of involved neural functions (Woody CD, ed), pp 581-599. New York: Plenum.

Kling A, Steklis HD, Deutsch S (1979) Radiotelemetered activity from the amygdala during social interactions in the monkey. Exp Neurol $66: 88-96$.

Kling AS, Brothers LA (1992) The amygdala and social behavior. In: The amygdala: neurobiological aspects of emotion, memory, and 
mental dysfunction (Aggleton JP, ed), pp 353-378. New York: WileyLiss.

Kosslyn SM, Alpert NM, Thompson WL, Maljkovic V, Weise SB, Chabris CF, Hamilton SE, Rauch SL, Buonanno FS (1993) Visual mental imagery activates topographically organized visual cortex: PET investigations. J Cogn Neurosci 5:263-287.

LeDoux JE, Iwata J, Cicchetti P, Reis DJ (1988) Different projections of the central amygdaloid nucleus mediate autonomic and behavioral correlates of conditioned fear. J Neurosci 8:2517-2529.

LeDoux JE, Cicchetti P, Xagoraris A, Romanski LM (1990) The lateral amygdaloid nucleus: sensory interface of the amygdala in fear conditioning. J Neurosci 10:1062-1069.

Lee GP, Arena JG, Meador KJ, Smith JR, Loring DW, Flanigin HF (1988a) Changes in autonomic responsiveness following bilateral amygdalotomy in humans. Neuropsychiatr Neuropsychol Behav Neurol 1:119-129.

Lee GP, Meador KJ, Smith JR, Loring DW, Flanigin HF (1988b) Preserved crossmodal association following bilateral amygdalotomy in man. Int $\mathbf{J}$ Neurosci 40:47-55.

Leonard CM, Rolls ET, Wilson FAW, Baylis GC (1985) Neurons in the amygdala of the monkey with responses selective for faces. Behav Rrain Res 15:159-176.

Markowitsch HJ, Calabrese P, Wuerker M, Durwen HF, Kessler J, Babinsky R, Brechtelsbauer D, Heuser L, Gehlen W (1994) The amygdala's contribution to memory a study on two patients with UrbachWiethe disease. Neuroreport 5:1349-1352.

McCarthy RA, Warrington EK (1990) Cognitive neuropsychology. New York: Acadentic.

Nahm FKD, Tranel D, Damasio H, Damasio AR (1993) Cross-modal associations and the human amygdala. Neuropsychologia 31:727744.

Narabayashi H (1972) Stereotaxic amygdalotomy. In: The neurobiology of the amygdala (Eleftheriou BE, ed), pp 459-483. New York: Plenum.

Niehoff DL, Kuhar MJ (1983) Benzodiazepine receptors: localization in rat amygdala. I Neurosci 3:2091-2097.

Nishijo H, Ono T, Nishino H (1988) Single neuron responses in amygdala of alert monkey during complex sensory stimulation with affective significance. J Neurosci 8:3570 3583.

Perrett DI, Rolls ET, Caan W (1982) Visual neurons responsive to faces in the monkey temporal cortex. Exp Brain Res 47:329-342.

Rapcsak SZ, Kaszniak AW, Rubens AB (1989) Anomia for facial ex- pressions: evidence for a category specific visual-verbal disconnection syndrome. Neuropsychologia 27:1031-1041.

Rapcsak SZ, Comer JF, Rubens AB (1993) Anomia for facial expressions: neuropsychological mechanisms and anatomical correlates. Brain Lang 45:233-252.

Rolls ET (1992) Neurophysiology and functions of the primate amygdala. In: The amygdala: neurobiological aspects of emotion, memory, and mental dysfunction (Aggleton JP, ed), pp 143-167. New York: Wiley-Liss.

Rosvold HE, Mirksy AF, Pribram K (1954) Influence of amygdalectomy on social behavior in monkeys. J Comp Physiol Psychol 47: $173-178$

Russell JA (1991) In defense of a prototype approach to emotion concepts. J Pers Soc Psychol 60:37-47.

Russell JA, Bullock M (1986) Fuzzy concepts and the perception of emotion in facial expressions. 4:309-341.

Russell JA, Fehr B (1987) Relativity in the perception of emotion in facial expressions. J Exp Psychol 116:223-237.

Saudou F, Amara DA, Dierich A, LeMeur M, Ramboz S, Segu L, Buhot M-C, Hen R (1994) Enhanced aggressive behavior in mice lacking 5-HT1B receptor. Science 265:1875-1878.

Stein NL, Leventhal B, Trabasso T (1990) Psychological and biological approaches to emotion. Hillsdale, NJ: LEA.

Tranel D (1995) The Iowa-Benton school of neuropsychological assessment. In: Neuropsychological assessment of neuropsychiatric disorders (Grant I, Adams KM, eds). New York: Oxford UP.

Tranel D, Hyman BT (1990) Neuropsychological correlates of bilateral anygdala damage. Arch Neurol 47:349-355.

Tranel D, Damasio AR, Damasio H (1988) Intact recognition of facial expression, gender, and age in patients with impaired recognition of face identity. Neurology 38:690-696.

Tranel D, Damasio H, Damasio AR (in press) Double dissociation between overt and covert face recognition. J Cogn Neurosci, in press.

Wachsmuth E, Oram MW, Perrett DI (1994) Recognition of objects and their component parts: responses of single units in the temporal cortex of the macaque. Cereb Cortex 4:509-522.

Weiskrantz L (1956) Behavioral changes associated with ablation of the amygdaloid complex in monkeys. J Comp Physiol Psychol 49: 381-391.

Young AW, Aggleton JP, Hellawell DJ, Johnson M, Broks P, Hanley JR (1995) Face processing impairments after amygdalotomy. Brain 118 : 15-24. 